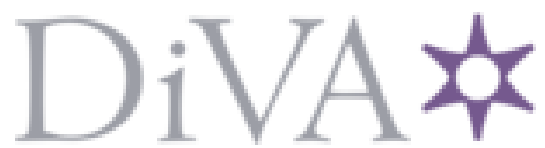

http://www.diva-portal.org

This is the published version of a paper published in Diabetes/Metabolism Research Reviews.

Citation for the original published paper (version of record):

Julin, B., Willers, C., Leksell, J., Lindgren, P., Muth, K L. et al. (2018)

Association between sociodemographic determinants and health outcomes in individuals with type 2 diabetes in Sweden

Diabetes/Metabolism Research Reviews, 34(4): -9

https://doi.org/10.1002/dmrr.2984

Access to the published version may require subscription.

N.B. When citing this work, cite the original published paper.

Permanent link to this version:

http://urn.kb.se/resolve?urn=urn:nbn:se:du-27115 


\title{
Association between sociodemographic determinants and health outcomes in individuals with type 2 diabetes in Sweden
}

\author{
Bettina Julin $^{1}$ | Carl Willers ${ }^{1,2}$ (D) | Janeth Leksell ${ }^{3,4}$ | Peter Lindgren ${ }^{5,6}$ | \\ Karin Looström Muth ${ }^{7}$ | Ann-Marie Svensson ${ }^{8}$ | Mikael Lilja9 | Tobias Dahlström ${ }^{10}$
}

${ }^{1}$ Ivbar Institute, Stockholm, Sweden

${ }^{2}$ Department for Clinical Science and Education, Karolinska Institutet, Stockholm, Sweden

${ }^{3}$ School of Education, Health and Social Studies, Dalarna University, Falun, Sweden

${ }^{4}$ Department of Medical Sciences, Uppsala University, Uppsala, Sweden

${ }^{5}$ Medical Management Centre, Karolinska Institutet, Stockholm, Sweden

${ }^{6}$ The Swedish Institute for Health Economics, Lund, Sweden

${ }^{7}$ Department of Internal Medicine, Alingsås Hospital, Alingsås, Sweden

${ }^{8}$ National Diabetes Register, Centre of Registers, Gothenburg, Sweden

${ }^{9}$ Department of Public Health and Clinical Medicine, Unit of Research, Education, and Development, Östersund, Umeå University, Umeå, Sweden

${ }^{10}$ Public Health and Caring Science, Uppsala University, Uppsala, Sweden

\section{Correspondence}

Carl Willers, Ivbar Institute, Hantverkargatan 8, 11221 Stockholm, Sweden.

Email: carl.willers@ivbar.com, carl.willers@ki.se

Funding information

Sveus; Forte, Grant/Award Number: 2012/ 1688

\begin{abstract}
Background: Concurrent multifactorial treatment is needed to reduce consequent risks of diabetes, yet most studies investigating the relationship between sociodemographic factors and health outcomes have focused on only one risk factor at a time. Swedish health care is mainly tax-funded, thus providing an environment that should facilitate equal health outcomes in patients, independent of background, socioeconomic status, or health profile. This study aimed at investigating the association between several sociodemographic factors and diabetes-related health outcomes represented by $\mathrm{HbA}_{1 \mathrm{c}}$, systolic blood pressure, low-density lipoprotein cholesterol, predicted 5-year risk of cardiovascular disease, and statin use.
\end{abstract}

Methods: This large retrospective registry study was based on patient-level data from individuals diagnosed with type 2 diabetes during 2010 to 2011 ( $n=416,228$ ) in any of 7 Swedish regions ( $65 \%$ of the Swedish population). Health equity in diabetes care analysed through multivariate regression analyses on intermediary outcomes $\left(\mathrm{HbA}_{1 \mathrm{c}}\right.$, systolic blood pressure, and low-density lipoprotein), predicted 5-year risk of cardiovascular disease and process (i.e., statin use) after 1-year follow-up, adjusting for several sociodemographic factors.

Results: We observed differences in intermediary risk measures, predicted 5-year risk of cardiovascular disease, and process dependent on place of birth, sex, age, education, and social setting, despite Sweden's articulated vision of equal health care.

Conclusions: Diabetes patients' health was associated with sociodemographic prerequisites. Furthermore, in addition to demographics (age and sex) and disease history, educational level, marital status, and region of birth are important factors to consider when benchmarking health outcomes, e.g., average $\mathrm{HbA}_{1 \mathrm{c}}$ level, and evaluating the level of health equity between organizational units or between different administrative regions.

\section{KEYWORDS}

type 2 diabetes mellitus, sociodemographics, $\mathrm{HbA}_{1 \mathrm{c}}$, systolic blood pressure, statin use, cardiovascular disease

\section{1 | INTRODUCTION}

Diabetes is one of the leading causes of death globally with an ever increasing prevalence; the age-standardized diabetes prevalence increased from $4.3 \%$ in 1980 to $9.0 \%$ in 2014 in men, and from 5.0\% to $7.9 \%$ in women. Type 2 diabetes mellitus stands for about 85 to
$90 \%$ of all cases. ${ }^{1}$ Recommendations for the management of type 2 diabetes mellitus include rigorous control of blood glucose levels and other risk factors, such as hypertension and dyslipidaemia. Furthermore, patients with type 2 diabetes mellitus are at high risk of cardiovascular disease (CVD)-the leading cause of death in these patients. Because of the adverse health effects related to the disease, 
diabetes is also accompanied by an economic burden on individuals as well as on health-care systems. ${ }^{2}$ In addition, diabetes have strong adverse effects on the labour market. ${ }^{2}$ Good diabetes care is crucial to delay the complications and limit the costs. Different patient groups are, however, unequally affected by type 2 diabetes mellitus, determined by, e.g., sex, age, and ethnicity. Socioeconomic inequalities are also reflected in diabetes care and are often associated with differences in process indicators of care and intermediate health outcomes, resulting in varying risks of both microvascular and macrovascular complications. ${ }^{3}$

The Swedish health-care system is mainly tax-funded; individual costs represent a minor fraction of actual costs. It aims at being a socially responsible system with a clear public commitment to ensure the health of all citizens. ${ }^{4}$ Thus, studying type 2 diabetes mellitus care in Sweden is of interest because Swedish health care provides an environment that should facilitate equal health outcomes in patients, independent of background, socioeconomic status, or health profile. The relationship between social determinants of health and health outcomes has been established but is not well understood. ${ }^{5}$ Previous literature point to differences in diabetes care between sociodemographic groups in differences in $\mathrm{HbA}_{1 \mathrm{c}}, \mathrm{CVD}$ risk, low-density lipoprotein ( $\mathrm{LDL}$ ) cholesterol and blood pressure. ${ }^{5-7}$ In addition, a large Swedish study based on the National Diabetes Register (NDR) showed that socioeconomic status (country of birth, education, income, marital status, and occupation) was a strong predictor of both cardiovascular and diabetes-related mortality. ${ }^{8}$ Most of the studies conducted so far, however, focused on only 1 risk factor (mainly glycaemic control) even if concurrent multifactorial treatment is needed to reduce consequent risks of diabetes. In addition, few studies simultaneously assessed the impact of multiple determinants on diabetes-related health outcomes, and many of the studies are limited by small sample sizes and low statistical power. The aim of this study was thus to investigate the association between several sociodemographic factors and health outcomes-represented by the intermediary risk measures $\mathrm{HbA}_{1 \mathrm{c}}$, systolic blood pressure, LDL cholesterol, and 5-year risk of CVD as well as a process measure: statin use-among Swedish individuals with prevalent type 2 diabetes mellitus.

\section{2 | MATERIALS AND METHODS}

Sveus is a research collaboration between 7 Swedish regions aiming at developing systems for value-based monitoring of health care, initially funded by the Swedish Ministry of Health and Social affairs. The research within Sveus diabetes is based on the extended research group (Sveus, www.sveus.se) representing county councils, the patient organization for diabetes in Sweden, specialists, the NDR, and the R\&D company Ivbar Institute.

\section{1 | Study population and data sources}

This retrospective registry study included individuals with type 2 diabetes mellitus, aged 18 years or older, with a health-care contact and a diagnosis of diabetes between January 1, 2010 and December 31, 2011 in the administrative systems of 7 Swedish county councils (Dalarna, Jämtland Härjedalen, Skåne, Stockholm, Uppsala, Västra
Götaland, and Östergötland), covering $\sim 65 \%$ of the Swedish population. Using the unique 12-digit personal identification number, we linked data from the NDR to data from the above-mentioned administrative systems, socioeconomic data from national databases operated by Statistics Sweden, and data on filled prescriptions from the Prescribed Drug Registry at the National Board of Health and Welfare. Individuals with type 2 diabetes mellitus were defined hierarchically according to the following: (1) having a type 2 diabetes mellitus registration within the NDR (coverage rate $\sim 90 \%$ at the time ${ }^{9}$ ) and/or (2) having care contacts with ICD-10 disease code E11 according to the patient administrative systems. To include only previously known cases of type 2 diabetes mellitus, patients diagnosed last year were excluded (data were available from 2007). Data were analysed as subsequent, 1-year care episodes; i.e., after completion of one episode, the next episode was automatically started. The first episode for an individual was started at the time of the diabetes diagnosis. Because most of the outcomes studied were not measured and registered exactly after 1 year, a span of \pm 3 months around the end of each episode was allowed. If more than 1 measurement was available for a specific outcome, the value closest to the end of the episode was used.

Ethical approval for the study was granted by the Regional Ethical Review Board in Stockholm, Sweden (no. 2013/1197-31). All individuals provided informed consent prior to inclusion in the NDR.

\section{3 | OUTCOMES}

The quality of diabetes care was evaluated based on 5 outcomes: absolute $\mathrm{HbA}_{1 \mathrm{c}}$ level after 1 year of follow-up, systolic blood pressure, LDL levels after 1 year of follow-up, predicted 5-year risk of CVD after 1 year of follow-up, ${ }^{10}$ and prescribed statins.

\section{1 | Traditional risk markers}

Traditional risk markers of diabetes care were collected from the NDR. Laboratory analyses of $\mathrm{HbA}_{1 \mathrm{c}}$ were performed at local health-care facilities associated with a quality assessment organization with regular validations. $\mathrm{HbA}_{1 \mathrm{c}}$ values are reported as $\mathrm{mmol} / \mathrm{mol}$ and percentage and were converted according to the National Glycohemoglobin Standardization Program. ${ }^{11}$ The standard for blood pressure measurement used in the NDR is the mean value $(\mathrm{mm} \mathrm{Hg})$ of 2 readings in the supine position using a cuff of appropriate size and after at least 5 minutes of rest. The latest guidelines for diabetes care by the Swedish National Board of Health and Welfare recommend a target blood pressure of $<140 / 85 \mathrm{~mm} \mathrm{Hg}^{12}$, although the target blood pressure at time of data collection was $<130 / 80 \mathrm{~mm} \mathrm{Hg}$. In the present study, we assessed both continuous systolic blood pressure as well as dichotomized blood pressure defined as under or equal to/above 140/85 mm Hg. Low-density lipoprotein cholesterol concentration $(\mathrm{mmol} / \mathrm{L})$ was based on Friedewald's formula. ${ }^{13}$

\section{2 | Predicted 5-year risk of CVD}

An algorithm to predict the 5-year risk for CVD in individuals with type 2 diabetes mellitus, aged 30 to 74 years, has previously been 
developed based on the NDR. ${ }^{10}$ The model is based on real-life data and includes 12 parameters: age at diagnosis, diabetes duration, total-cholesterol/HDL-cholesterol ratio, $\mathrm{HbA}_{1 \mathrm{c}}$, systolic blood pressure, BMI, sex, smoking status, micro and macro albuminuria, atrial fibrillation, and previous CVD (last two years). In the present analysis and in accordance with the NDR-based model, only values between BMI 16 and 50 and concentrations between 20 and $800 \mu \mathrm{mol} / \mathrm{L}$ in creatinine were included as well as individuals aged 30 to 74 years. Previous CVD was defined as having angina pectoris, acute or subsequent myocardial infarction, complications following acute myocardial infarction, other acute ischemic heart diseases, chronic ischemic heart disease, intracerebral haemorrhage, cerebral infarction, stroke (ICD-10 codes 120-125, I61, 163, or 164), or percutaneous coronary intervention and/or coronary artery bypass grafting (Nomesco Classification of Surgical Procedures: FNA, FNB, FNC, FND, FNE, FNF, or FNG) ${ }^{14}$ registered in the patient administrative systems.

\section{3 | Statin use}

We used information on filled statin prescriptions identified from the Swedish Prescribed Drug Registry as a proxy for statin use. Statins were defined as Anatomical Therapeutic Chemical classification codes C10AA01-08

\section{4 | CASEMIX FACTORS}

Casemix factors were selected based on the literature, the clinical expertise of the multiprofessional expert group, and data availability. Sociodemographic factors included age, sex, educational level, marital status, and region of birth. Duration of diabetes and baseline levels of $\mathrm{BMI}$, smoking status, $\mathrm{HbA}_{1 \mathrm{c}}$, estimated glomerular filtration rate (eGFR; estimated with the revised Lund-Malmo formula), ${ }^{15}$ systolic blood pressure, and LDL cholesterol were identified via the NDR. Comorbidities (last two years) were identified via ICD-10 codes in the regional administrative systems with main or secondary diagnosis: 120-I25, 161, 163-I64 (CVD), H431 (eye disease), E116D (lower extremity complications), N185, Y841, Z491-Z492, Y992 (renal failure), 148 (atrial fibrillation), F32 (episode of depression), and F0, F1, F2, and F7 (other psychiatric conditions). For some conditions, the Nomesco Classification of Surgical Procedures codes were used for the same purpose: FNA-FNG (CVD), NHQ, NGQ09, NGQ19, NGQ99 (lower extremity complications), DR014-DR016, DR023-DR024, and QF006 (renal failure).

\section{5 | STATISTICAL ANALYSIS}

Multivariate regression analysis was performed for each of the 5 outcomes assessed. The dependent variables $-\mathrm{HbA}_{1 \mathrm{c}}$ level, systolic blood pressure, LDL level, and predicted 5-year risk of CVD-were treated as continuous variables and modelled by using ordinary least squares regression. Blood pressure below or equal/greater to 140/85 mm Hg as well as statin use were treated dichotomously and modelled by using logistic regression.

All models were adjusted for age (grouped in 5-year intervals), sex (male/female), highest level of education ( $\leq 9$ years, $10-12$ years, and $>12$ years), region of birth (within the Nordic countries, the European Union [EU], Europe but not the EU, or outside Europe), and marital status (married, never married, divorced, and widowed). Additional casemix factors for each specific outcome are described in Table 1. To assess the impact of the casemix factors on the study variables, regression analysis was adjusted for clustering of health outcomes within individual patients when computing the $95 \%$ confidence intervals (Cls) of each casemix factor's effect on the outcome, as some patients contributed with two 1-year episodes. Multiplicative interactions were tested by using the likelihood ratio test. Two-sided $P$ values less than .05 were considered statistically significant.

\section{6 | RESULTS}

The study population consisted of 537,025 one-year episodes of previously known type 2 diabetes mellitus registered during 2010 to

TABLE 1 Casemix factors for each specific outcome analysed

\begin{tabular}{|c|c|c|c|c|c|}
\hline & \multicolumn{5}{|l|}{ Outcome } \\
\hline & HbA1c & Systolic Blood Pressure & LDL Cholesterol & $\begin{array}{l}\text { 5-Year Risk of } \\
\text { Cardiovascular } \\
\text { Disease }\end{array}$ & Statin Use \\
\hline $\begin{array}{l}\text { Common } \\
\text { Casemix } \\
\text { Factors }\end{array}$ & \multicolumn{5}{|c|}{ Age, Sex, Highest Level of Education, Region of Birth, and Marital Status } \\
\hline $\begin{array}{l}\text { Additional } \\
\text { casemix } \\
\text { factors }\end{array}$ & $\begin{array}{l}\text { BMI (cont.), duration } \\
\text { of diabetes (in years), } \\
\text { smoking status (yes/no), } \\
\text { and disease history }{ }^{a}\end{array}$ & $\begin{array}{l}\text { eGFR at baseline (cont.), } \\
\text { BMI (cont.), duration } \\
\text { of diabetes (in years), } \\
\text { HbA1c at baseline } \\
\text { (cont.), LDL at baseline } \\
\text { (cont.), smoking status } \\
\text { (yes/no), and disease } \\
\text { history }^{\text {a }}\end{array}$ & $\begin{array}{l}\text { eGFR at baseline (cont.), } \\
\text { BMI (cont.), duration of } \\
\text { diabetes (in years), HbA1c } \\
\text { at baseline (cont.), systolic } \\
\text { blood pressure (cont.), } \\
\text { smoking status (yes/no), } \\
\text { and disease history }{ }^{\mathrm{a}}\end{array}$ & $\begin{array}{l}\text { eGFR at baseline } \\
\text { (cont.) and } \\
\text { disease history }{ }^{\mathrm{a}}\end{array}$ & $\begin{array}{l}\text { eGFR at baseline (cont.), } \\
\text { BMI (cont.), duration } \\
\text { of diabetes (in years), } \\
\text { HbA1c at baseline } \\
\text { (cont.), systolic blood } \\
\text { pressure (cont.), LDL at } \\
\text { baseline (cont.), } \\
\text { smoking status (yes/no), }_{\text {and disease history }}{ }^{a}\end{array}$ \\
\hline $\begin{array}{c}\text { No. of episodes } \\
\text { per analysis }\end{array}$ & 82,469 & 55,865 & 51,124 & 3,387 & 83,640 \\
\hline
\end{tabular}

${ }^{a}$ Event of cardiovascular disease, eye disease, lower extremity complications, renal failure, atrial fibrillation, depression, or other psychiatric conditions during the previous 2 years. 
2011 with available information from the NDR and the administrative systems. After excluding episodes with missing values on casemix variables common for all outcomes studied, 416,228 one-year episodes (219,598 unique prevalent type 2 diabetes mellitus patients) remained. Of these, the numbers of episodes per outcome studied were as follows: $\mathrm{HbA}_{1 \mathrm{c}}(\mathrm{n}=82,469)$, systolic blood pressure ( $n=55,865)$, LDL cholesterol ( $n=51,124), 5$-year CVD risk score ( $n=3,387)$, and statin use ( $n=83,640)$. Baseline characteristics of the study population are presented in Table 2 . The mean diabetes duration was 9.8 (SD 7.89) years, and the mean age was 68.0 (SD 12.6) years with most being men (58.8\%), married $(50.9 \%)$, and born within the Nordic countries (85.4\%). Around 18\% had completed college/university.

\section{7 | DETERMINANTS OF TRADITIONAL RISK MARKERS}

Results from the multivariate regression analysis on $\mathrm{HbA}_{1 c}$ level after 1 year are presented in Figure 1 . Women had lower levels of $\mathrm{HbA}_{1 \mathrm{c}}$ levels compared with men $(P=.01)$. Glucose control varied between age groups with the youngest individuals having the highest levels of $\mathrm{HbA}_{1 \mathrm{c}}$. Lower education was consistently associated with higher levels of $\mathrm{HbA}_{1 \mathrm{c}}$. Being married was associated with lower $\mathrm{HbA}_{1 \mathrm{c}}$ levels compared with never married individuals $(P<.001)$. Being born in Europe outside of the EU or being born outside Europe was associated with higher $\mathrm{HbA}_{1 \mathrm{c}}$ levels $(P<.001$ for both). Smoking $(P=.002)$, duration of diabetes (per year, $P<.001)$ and BMI (per unit, $P<.001$ ) were all individually associated with higher levels of HbA1c. A history (previous two years) of CVD $(P<.001)$, eye disease $(P=.006)$, or lower extremity complications $(P=.004)$ were associated with higher levels of $\mathrm{HbA}_{1 \mathrm{c}}$. Coefficients are presented in Table S1.

Results from the multivariate regression analysis on blood pressure are presented in Figure 2. When modelling systolic blood pressure continuously, in addition to higher age, lower educational level was associated with higher systolic blood pressure $(P=.002$ for educational level $<9$ years and $P<.001$ for educational level 10 12 years compared with educational level of $>12$ years). Being married $(P<.001)$ or being divorced $(P=.004)$ was associated with lower systolic blood pressure compared with never being married. Region of birth was associated with systolic blood pressure; being born in a non-EU European country was associated with higher systolic blood pressure $(P=.01)$, whereas being born outside Europe was associated with lower systolic blood pressure $(P<.001)$ compared with being born within the Nordic countries. Both estimated GFR (per unit, $P<.001$ ), $\mathrm{HbA}_{1 \mathrm{c}}$ (per unit, $P<0.001$ ), LDL (per unit, $P<.001$ ) and BMI (per unit, $P=.009)$ at baseline were associated with higher blood pressure. $A$ history (previous two years) of atrial fibrillation, depressive episode, or other psychiatric conditions were associated with lower systolic blood pressure $(P<.001, P=.004$, and $P<.001$, respectively). Coefficients are presented in Table S2.

We also assessed the effect of sociodemographic and other baseline determinants on the risk of having a blood pressure above 140/85 mm Hg (Figure S1). The pattern between the determinants
TABLE 2 Baseline characteristics of 416,228 one-year episodes of prevalent type 2 diabetes mellitus, 2010 to 2011

\begin{tabular}{|c|c|c|}
\hline Characteristic & Value & No. of Episodes \\
\hline Age, mean (SD) & $68.0(12.6)$ & 416,228 \\
\hline Female, \% & 41.2 & 416,228 \\
\hline \multicolumn{3}{|l|}{ Education (highest level) } \\
\hline Elementary school, \% & 41.4 & 416,228 \\
\hline High school, \% & 40.9 & 416,228 \\
\hline College/university, \% & 17.7 & 416,228 \\
\hline \multicolumn{3}{|l|}{ Marital status } \\
\hline Unmarried, \% & 15.1 & 416,228 \\
\hline Married, \% & 50.9 & 416,228 \\
\hline Divorced, \% & 18.2 & 416,228 \\
\hline Widow/widower, \% & 15.8 & 416,228 \\
\hline \multicolumn{3}{|l|}{ Region of birth } \\
\hline The Nordic countries, \% & 85.4 & 416,228 \\
\hline $\begin{array}{l}\text { The European Union } \\
\text { (EU), \% }\end{array}$ & 3.7 & 416,228 \\
\hline Europe outside the EU, \% & 3.5 & 416,228 \\
\hline Outside Europe, \% & 7.3 & 416,228 \\
\hline $\begin{array}{l}\text { Body mass index }\left(\mathrm{kg} \mathrm{m}^{-2}\right) \text {, } \\
\text { mean (SD) }\end{array}$ & $29.7(5.2)$ & 153,486 \\
\hline $\begin{array}{l}\text { Duration of diabetes (years), } \\
\text { mean (SD) }\end{array}$ & $9.8(7.8)$ & 177,267 \\
\hline Current smoker, \% & 17.4 & 416,228 \\
\hline \multicolumn{3}{|l|}{ Disease history } \\
\hline Cardiovascular disease $^{\mathrm{a}}, \%$ & 33.6 & 416,228 \\
\hline Eye disease $^{\mathrm{b}}, \%$ & 5.6 & 416,228 \\
\hline $\begin{array}{l}\text { Lower extremity } \\
\text { complication } / \mathrm{s}^{\mathrm{c}}, \%\end{array}$ & 1.1 & 416,228 \\
\hline Renal failure $^{d}, \%$ & 0.7 & 416,228 \\
\hline Atrial fibrillation, \% & 8.5 & 416,228 \\
\hline Depression, \% & 1.8 & 416,228 \\
\hline $\begin{array}{l}\text { Other psychiatric } \\
\text { condition } / \mathrm{s}^{\mathrm{e}}, \%\end{array}$ & 3.2 & 416,228 \\
\hline $\begin{array}{l}\text { HbA1c at baseline, \%; SD } \\
(\mathrm{mmol} / \mathrm{mol} ; \mathrm{SD})^{f}\end{array}$ & 7.2; $3.4(55.1 ; 13.4)$ & 179,685 \\
\hline $\begin{array}{l}\text { eGFR at baseline, } \mathrm{mL} / \mathrm{min} \\
\text { per } 1.73 \mathrm{~m}^{2}(\mathrm{SD})\end{array}$ & $70.3(19.7)$ & 166,082 \\
\hline $\begin{array}{l}\text { Systolic blood pressure at } \\
\text { baseline, } \mathrm{mm} \mathrm{Hg} \text { (SD) }\end{array}$ & $135.7(16.1)$ & 171,021 \\
\hline $\begin{array}{l}\text { LDL cholesterol at baseline, } \\
\mathrm{mmol} / \mathrm{L} \text { (SD) }\end{array}$ & $2.7(0.9)$ & 125,891 \\
\hline
\end{tabular}

aCD-10 codes: 120-125 (angina pectoris, myocardial infarction, other acute ischemic heart diseases, and chronic ischemic heart disease), 161 (intracerebral haemorrhage), and 163-164 (cerebral infarction and stroke not specified as haemorrhage or infarction).

bICD-10 codes: H431 (vitreous haemorrhage).

'ICD-10 codes: E116D (type 2 diabetes mellitus with foot ulcer).

dICD-10 codes: N185 (chronic kidney disease, stage 5), Y841 (kidney dialysis), Z491-Z492 (extracorporeal dialysis and other dialysis), and Y992 (dependence on renal dialysis).

eICD-10 codes: FO (organic, including symptomatic, and mental disorders), F1 (mental and behavioural disorders due to psychoactive substance use), F2 (schizophrenia), and F7 (mild mental retardation).

fIFCC units were converted to DCCT percentage units.

and dichotomous blood pressure was the same as compared with modelling systolic blood pressure continuously. 


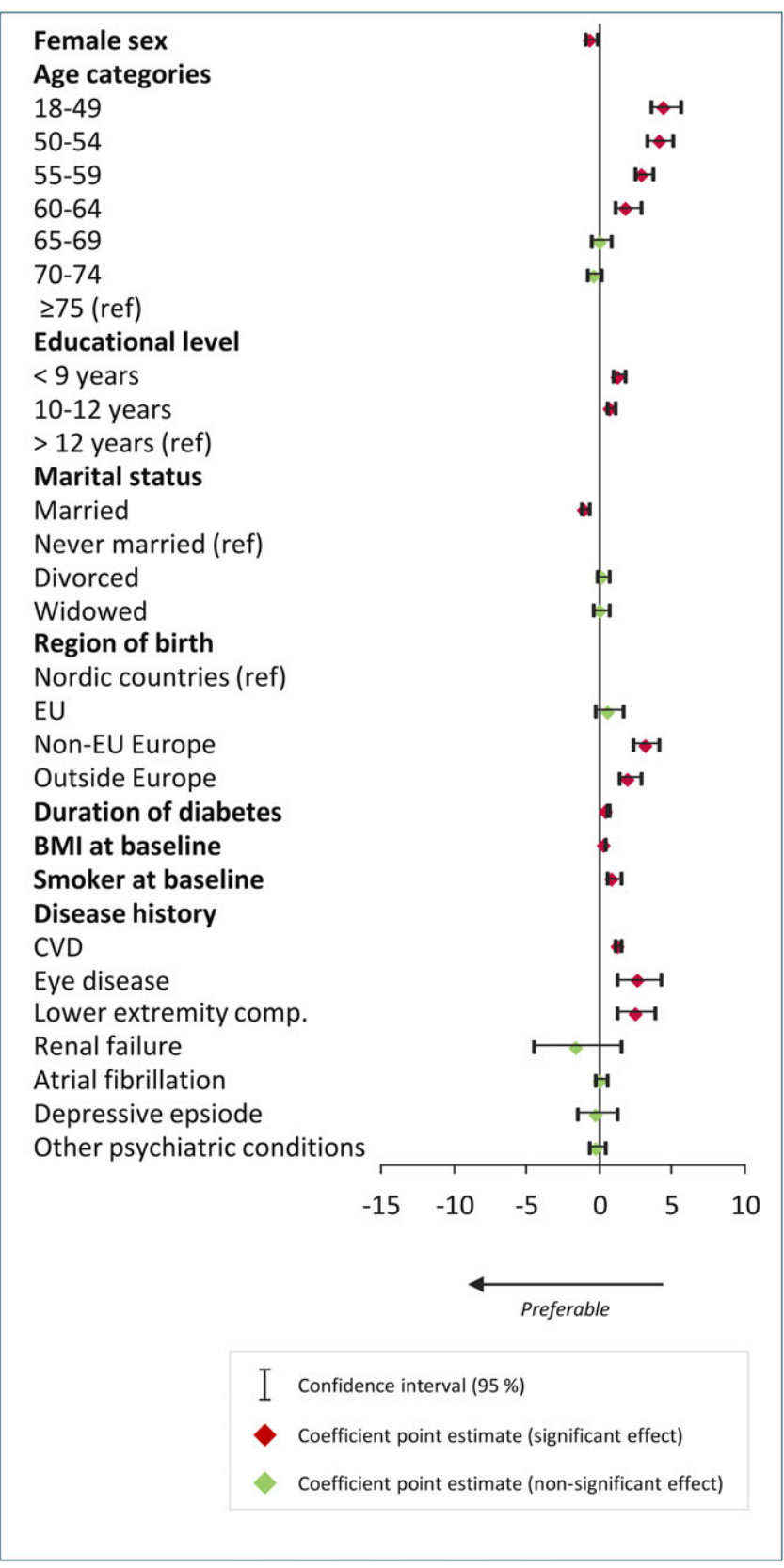

FIGURE 1 Multivariate regression of baseline characteristics of individuals with type 2 diabetes and $\mathrm{HbA}_{1 \mathrm{c}}$ levels ( $\mathrm{mmol} / \mathrm{L}$ ) after 1 year (82,469 episodes). Coefficient point estimates and their $95 \%$ confidence intervals

Results from the multivariate regression analysis on LDL levels are presented in Figure 3.

Being a woman was associated with higher LDL levels as compared with being a man $(P<.001)$. Age did not seem to be associated with LDL levels, with the exception of the youngest age group; individuals 18 to 49 years of age had higher LDL levels compared with those $\geq 75$ years of age $(P=.003)$. Estimated GFR levels at baseline were associated with higher LDL levels (per unit, $P<.001$ ), whereas duration of diabetes (per year, $P<.001$ ) and BMI at baseline (per unit, $P<.001$ ) were associated with lower levels of LDL. A history (previous two years) of CVD $(P<.001)$ and a history of atrial fibrillation $(P=.002)$ were both associated with lower levels of LDL. Coefficients are presented in Table S3.

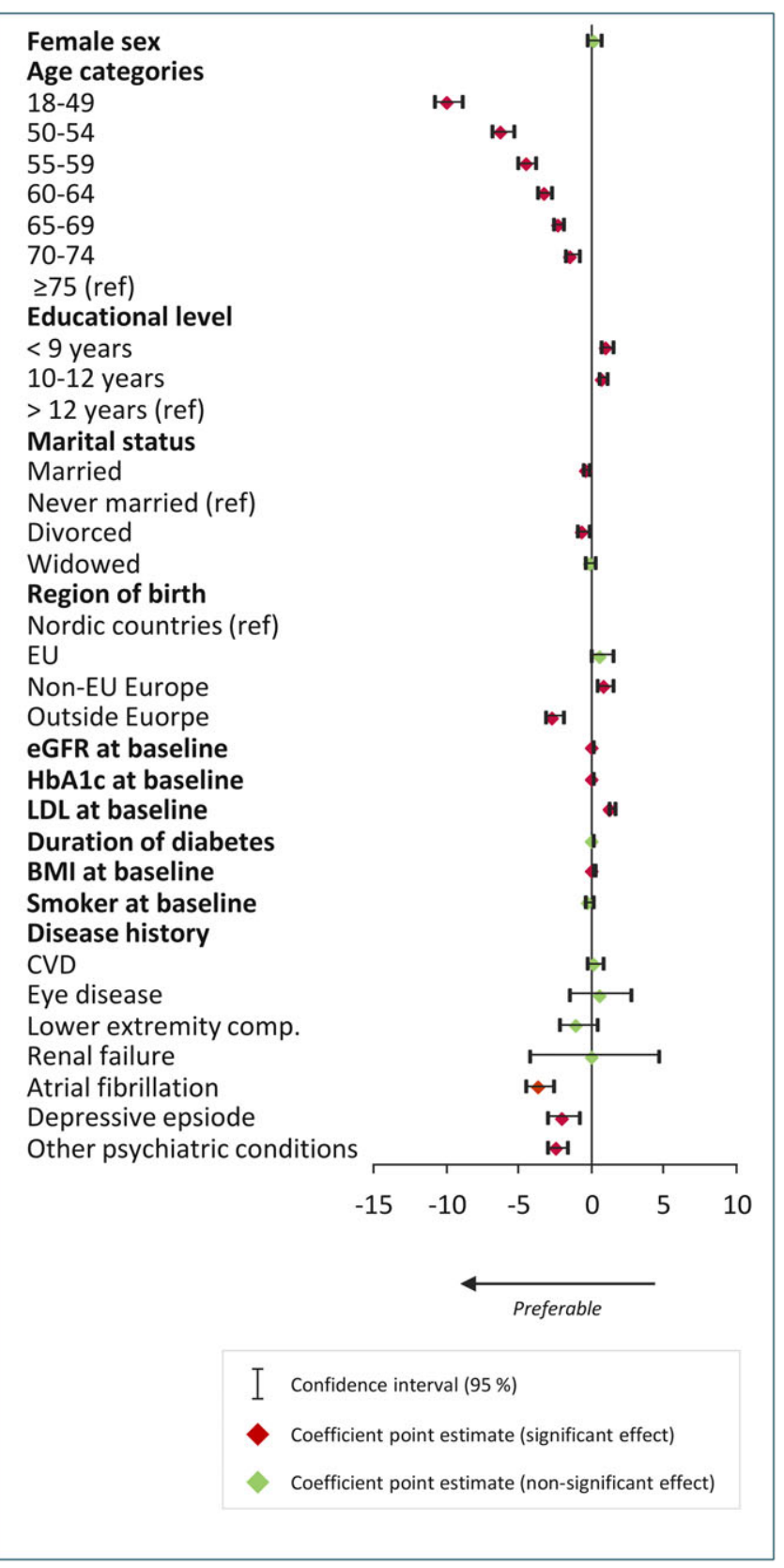

FIGURE 2 Multivariate regression of baseline characteristics of individuals with type 2 diabetes and continuous systolic blood pressure after 1-year follow-up (55,865 episodes). Coefficient point estimates and their $95 \%$ confidence intervals

\section{8 | DETERMINANTS OF PREDICTED 5-YEAR RISK OF CVD}

Results from the multivariate regression analysis on estimated 5-year risk of CVD are presented in Figure 4. Being a woman was associated with lower CVD risk $(P<.001)$ as well as being younger $(P<.001$ for all age groups compared with being 65-74 years of age). Lower education was consistently associated with higher 5-year risk of CVD, high school education versus college/university degree $(P=.04)$, and comprehensive school versus college/university degree $(P=.01)$. Being born in Europe, but outside of the EU, or being born outside Europe was also associated with a higher 5-year risk of CVD $(P=.003$ and $P<.001$, respectively) compared with being born within the Nordic 


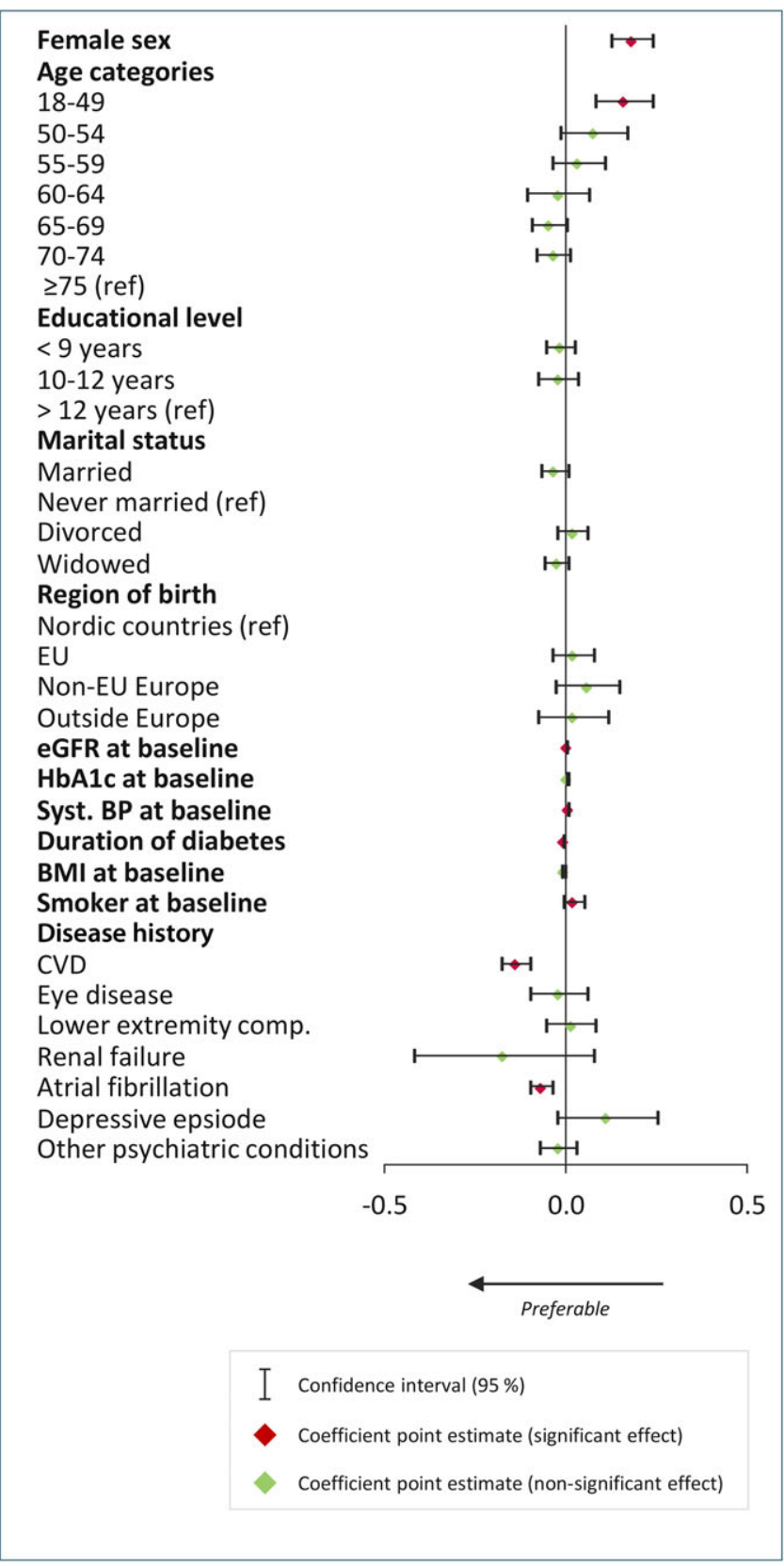

FIGURE 3 Multivariate regression of baseline characteristics of individuals with type 2 diabetes and low-density lipoprotein cholesterol after 1-year follow-up (51,124 episodes). Coefficient point estimates and their $95 \%$ confidence intervals

countries. Higher estimated GFR level at baseline was associated with a slightly lower risk of cardiovascular event within 5 years $(P<.001)$. A history (previous two years) of diabetes-related complications was, in general, associated with higher 5-year risk of CVD, with the exception of renal failure $(P=.13)$ and depressive episode $(P=.30)$. Coefficients are presented in Table S4.

The predictive model for 5-year risk of CVD used in this study was validated for the age span of 30 to 74 years $^{10}$; thus, we used the same age span in our analysis. As a sensitivity analysis, we also modelled the predicted 5-year risk of CVD by using the whole population, i.e., aged 18 years or older. Results did not differ substantially from the analysis including individuals aged 30 to 74 years only (data not shown). In addition, comparison of a number of baseline characteristics such as

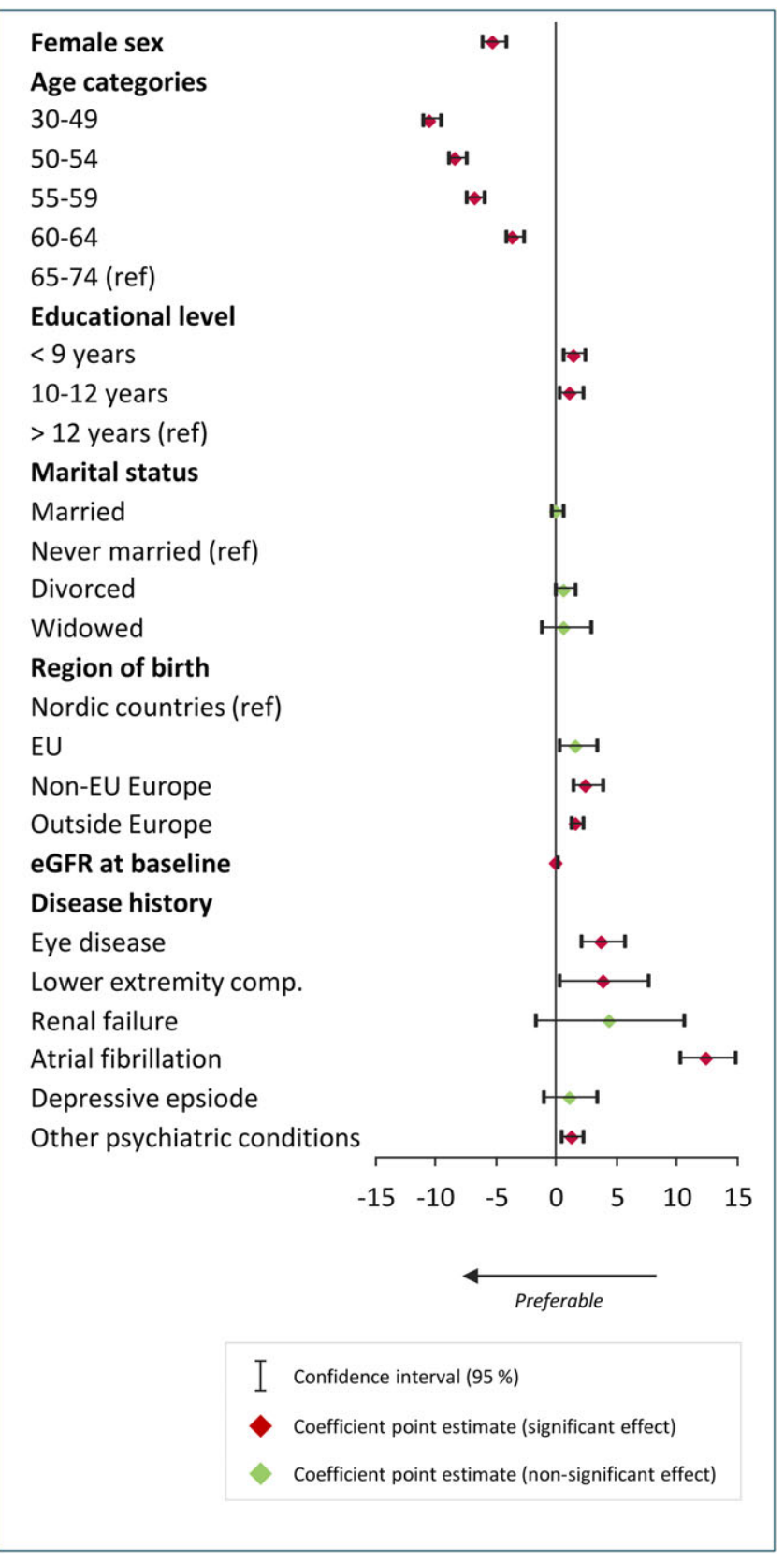

FIGURE 4 Multivariate regression of baseline characteristics of individuals aged 30 to 74 years with type 2 diabetes and 5-year predicted risk of cardiovascular disease; 1-year follow-up (3,387 episodes). Coefficient point estimates and their $95 \%$ confidence intervals

$\mathrm{BMI}$, diabetes duration, and $\mathrm{HbA}_{1 \mathrm{c}}$ between the group analysed and the total study population showed no notable differences (data not shown).

\section{9 | DETERMINANTS OF STATIN USE}

Results from the multivariate regression analysis on statin use are presented in Figure 5. Being in the age group 18 to 49 years was associated with lower statin use (odds ratio [OR] $0.75,95 \% \mathrm{Cl}$ : 0.65-0.86), whereas being 50 to 74 years was associated with increased statin use $(P=.01$ for ages $50-54$ and $P<0.01$ for all 


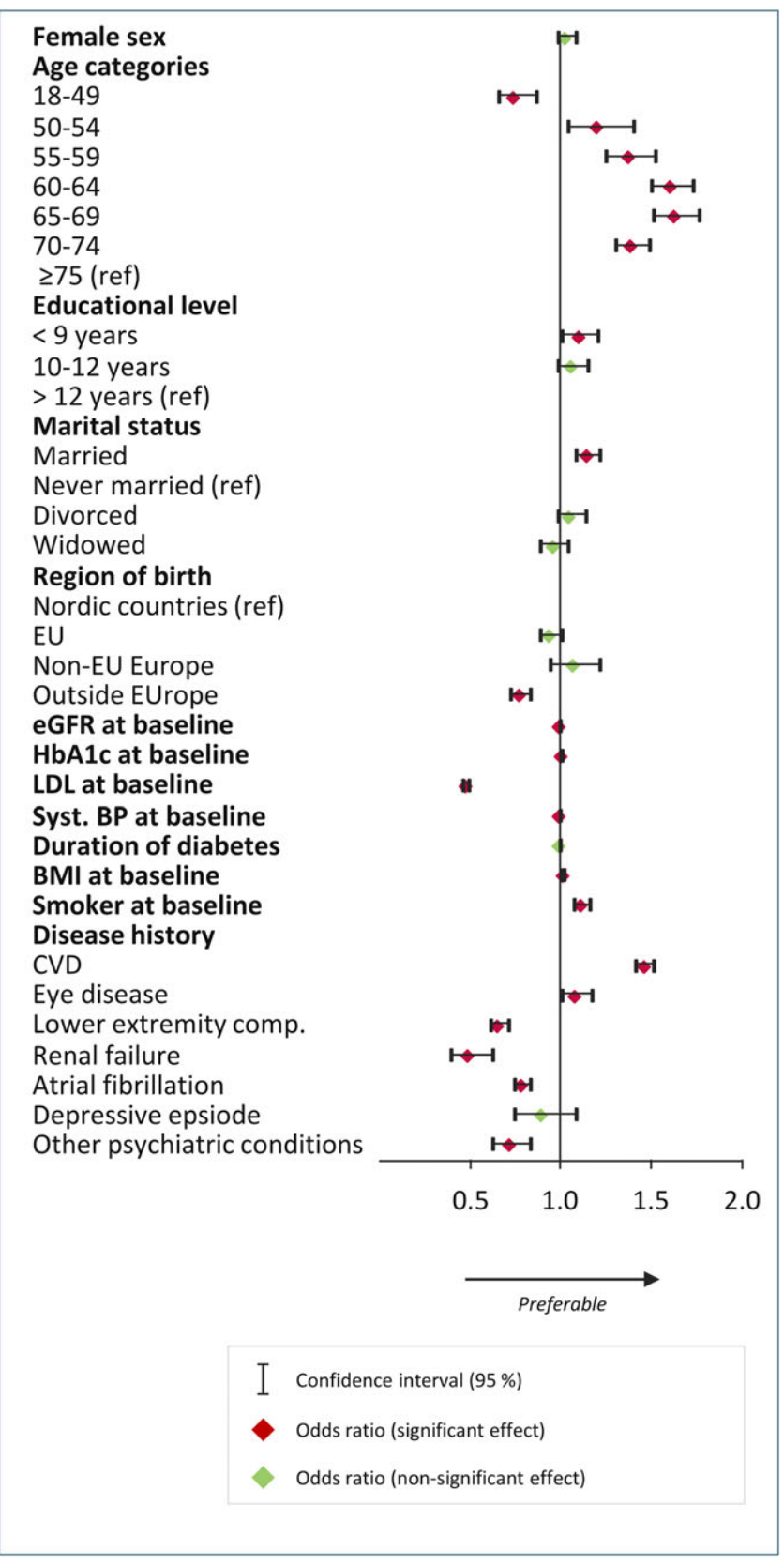

FIGURE 5 Multivariate regression of baseline characteristics of individuals with type 2 diabetes and filled prescriptions of statins after 1-year follow-up (83,640 episodes). Odds ratios and their $95 \%$ confidence intervals

older age groups), as compared with being 75 years or older. Individuals with lower education had $10 \%$ higher odds of statin use (OR 1.10; $95 \% \mathrm{Cl}$ : 1.01-1.21 for comprehensive school vs. college/university degree). Compared with never married individuals, being married was also associated with higher statin use (OR 1.15; 95\% Cl: 1.08-1.21). Individuals born outside Europe had 22\% lower odds of statin use (OR $0.78,95 \% \mathrm{Cl}$ : 0.72-0.83) compared with those born within the Nordic countries. $\mathrm{HbA}_{1 \mathrm{c}}$ as well as $\mathrm{BMI}$ at baseline were weakly associated with higher statin use (per unit, OR 1.01; $95 \% \mathrm{Cl}: 1.01-1.01$ and OR 1.01; $95 \% \mathrm{Cl}$ : 1.01-1.02, respectively). Low-density lipoprotein level was strongly associated with statin use (per unit OR 0.48; 95\% Cl: 0.46-0.50). Being a smoker at baseline was associated with $12 \%$ increased odds for statin use (OR 1.12; 95\% Cl: 1.07-1.16) compared with being a nonsmoker. A history of diabetes-related complications was associated with statin use, whereas having had a depressive episode was not. The strongest association was found for individuals with a history of renal failure (OR 0.50; $95 \% \mathrm{Cl}: 0.39$ to 0.63 ) as compared to those without. Coefficients are presented in Table S5.

We also investigated whether the association between region of birth and each specific outcome was modified by educational level. Among individuals with comprehensive school or a college/university degree as highest educational level, born within the EU appeared to be associated with a higher $\mathrm{HbA}_{1 \mathrm{c}}$ level, whereas for individuals with a high school degree, no statistically significant association was observed ( $P$ for interaction $=.04$ ). Among individuals with comprehensive school as highest educational level, born outside Europe appeared to be somewhat weaker associated with 5-year risk of CVD compared with those with a high school or college/university degree ( $P$ for interaction <.001). We did not observe any support for a modification by educational level for the other outcomes assessed ( $P$ for interaction $=.68$ for systolic blood pressure, .75 for LDL levels, and .31 for prescribed statins).

\section{0 | DISCUSSION}

In this retrospective registry study on individuals with prevalent type 2 diabetes mellitus in Sweden, we observed casemix-adjusted (place of birth, sex, age, education, and social setting) differences in intermediary risk measures and process as well as predicted 5-year risk of CVD, in conflict with Sweden's articulated vision of equal health care.

The previous studies conducted within this area have often been of small sample sizes, have not assessed several diabetesrelated outcomes, or have not adjusted for important covariates. However, our findings of associations between socioeconomic status characteristics or social determinants and $\mathrm{HbA}_{1 \mathrm{c}}$ levels are in line with most previous research conducted, but not all. ${ }^{16}$ An American study on individuals with type 2 diabetes mellitus $(n=615)$ found that $\mathrm{HbA}_{1 \mathrm{c}}$ was significantly negatively associated with more than college education ( $\beta=-0.72,95 \% \mathrm{Cl}-1.36,-0.08)$. Moreover, in line with the present study, systolic blood pressure was significantly negatively associated with college education $(\beta=-5.47, \mathrm{Cl}-10.49$, -0.44), whereas LDL was not associated with socioeconomic or psychological factors. ${ }^{6}$ A Finnish study ( $n=10,204$ ) found that female sex as well as higher education were associated with a higher proportion of achieving the recommended $\mathrm{HbA}_{1 \mathrm{c}}$ level (defined as less than $7 \%$ ). ${ }^{17}$ A Swedish study including 5,048 individuals, aged 35 to 74 years, with diagnosed type 2 diabetes mellitus, found that women were more likely to reach the recommended levels of $\mathrm{HbA}_{1 \mathrm{c}}$

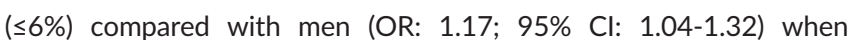
controlling for age, country of birth, education, and family income. ${ }^{18}$ Also, older individuals (65-74 years) were more likely to reach recommended $\mathrm{HbA}_{1 \mathrm{c}}$ levels compared with those aged 55 to 64 (OR: 1.18 95\% Cl: 1.03-1.35), whereas individuals born in Middle Eastern countries or non-European, Western countries were less 
likely to reach recommended $\mathrm{HbA}_{1 \mathrm{c}}$ levels compared with those born in Sweden (ORs 0.65; 95\% Cl: 0.54-0.79 for both groups). For LDL cholesterol, men were more likely to reach the recommended levels ( $\leq 2.5 \mathrm{mmol} / \mathrm{L}$ ); OR for women: 0.79 (95\% Cl: 0.68-0.91). ${ }^{18} \mathrm{~A}$ UK study of 1,534 individuals with type 2 diabetes mellitus found that several patient factors were related to glycaemic control; ${ }^{19}$ in univariate analyses, a 1-year increase in age was associated with a significant reduction (0.01\%) and a 1-unit increase in BMI with a significant increase $(0.04 \%)$ in $\mathrm{HbA}_{1 \mathrm{c}}$ concentration. There was also a dose-response relationship between years since diagnosis and $\mathrm{HbA}_{1 \mathrm{c}}$ concentration. In multivariable analyses, $\mathrm{HbA}_{1 \mathrm{c}}$ levels were significantly higher in individuals with a higher $\mathrm{BMI}$ and those who had been diagnosed with diabetes for more than 5 years. ${ }^{19}$ Another UK study ( $n=10,161$ ) found that higher BMI was associated with lower odds of achieving intermediate outcome targets for blood pressure (OR: 0.49; $95 \% \mathrm{Cl}$ : 0.40-0.60 when comparing $\mathrm{BMI} \geq 40$ to $\mathrm{BMI}<25$ ) and $\mathrm{HbA}_{1 \mathrm{c}}$ (OR: 0.54; 95\% Cl: 0.45-0.64 when comparing $\mathrm{BMI} \geq 40$ to $\mathrm{BMI}<25)$. Results were adjusted for age, sex, deprivation, BMI, and duration of diabetes. ${ }^{20}$ In a Hong Kong-based study of 1,970 patients with type 2 diabetes mellitus, patients in successive older age groups were more likely to achieve the $\mathrm{HbA}_{1 \mathrm{c}}$ target $(\leq 7 \%$; $P$ for trend $<.01) .{ }^{21}$ Women were $17 \%$ less likely to achieve the $\mathrm{HbA}_{1 \mathrm{c}}$ target compared with men $(P=.04)$.

The strengths of this study include a large sample size-covering most Swedish individuals with type 2 diabetes mellitus-and the ability to adjust for a broad range of sociodemographic factors and diabetesrelated complications due to the unique linkage of data from patient administrative systems, the NDR, Statistics Sweden, and the Prescribed Drug Registry. In addition, the Swedish Healthcare Quality Registries (whereof the NDR is 1 ) are of recognized high quality with a high proportion of completeness (in the case of NDR: 75\% overall and $>90 \%$ in certain subgroups), thus enabling collection of detailed information on disease-specific data. ${ }^{22}$ Validation studies of the NDR have also shown a high level of accuracy. ${ }^{23}$ There are, however, several limitations. This study was based on available retrospective registry data, not allowing for control of a potential systematic bias in registration of data. The analysis of determinants of 5-year risk for CVD excluded a large number of episodes due to the high number of parameters included in the algorithm (only 3,387 of 416,228 episodes could be included in this analysis). In addition, the algorithm was only validated for the age range of 30 to 74 years, which limited the number of observations included in the analysis additionally. The implications of our findings must also be considered within the context of the time period available for examination as diabetes care processes could have changed during later years. In addition, generalizations regarding other regions and other countries (also subject to other health-care systems) should be made with caution.

Based on findings from the present study, we conclude that diabetes care in Sweden is unequal. In addition to demographic factors (age and sex) and disease history, educational level, marital status, and region of birth are important factors to take into consideration when benchmarking health outcomes, e.g., average $\mathrm{HbA}_{1 \mathrm{c}}$ level, and evaluating the level of health equity between organizational units or between different administrative regions. These results highlight the importance of more personcentred care based on individual and sociodemographic needs.

\section{ACKNOWLEDGEMENTS}

We would like to thank all participating regions as well as the members of the Sveus diabetes expert group not contributing as authors: Gudrun Andersson, Inga-Lena Andersson, Mette Axelsen, Robert Kristiansson, Agneta Lindberg, and Fredrik Löndahl. Funding was provided by Sveus, a research collaboration with 7 Swedish regions developing systems for value-based monitoring of health care. Partial funding from Forte programme grant 2012/1688 ("value and choice") is gratefully acknowledged.

\section{DISCLOSURE OF INTERESTS}

BJ and CW are employed by Ivbar Institute, a research company specialized in health-care governance and analysis of health-care data. Other authors state no disclosures.

\section{ORCID}

Carl Willers (D) http://orcid.org/0000-0002-7616-9238

\section{REFERENCES}

1. Worldwide trends in diabetes since 1980: a pooled analysis of 751 population-based studies with 4.4 million participants. Lancet. 2016;387(10027):1513-1530.

2. Seuring T, Archangelidi O, Suhrcke M. The economic costs of type 2 diabetes: a global systematic review. Pharmaco Economics. 2015;33(8):811-831

3. Grintsova O, Maier W, Mielck A. Inequalities in health care among patients with type 2 diabetes by individual socio-economic status (SES) and regional deprivation: a systematic literature review. Int $J$ Equity Health. 2014;13(1):43.

4. Anell A, Glenngård AH, S M. Sweden: health system review. 2012.

5. Walker RJ, Smalls BL, Campbell JA, Strom Williams JL, Egede LE. Impact of social determinants of health on outcomes for type 2 diabetes: a systematic review. Endocrine. 2014;47(1):29-48.

6. Walker RJ, Gebregziabher M, Martin-Harris B, Egede LE. Independent effects of socioeconomic and psychological social determinants of health on self-care and outcomes in type 2 diabetes. Gen Hosp Psychiatry. 2014;36(6):662-668.

7. Doshi T, Smalls BL, Williams JS, Wolfman TE, Egede LE. Socioeconomic status and cardiovascular risk control in adults with diabetes. Am J Med Sci. 2016;352(1):36-44.

8. Rawshani A, Svensson AM, Zethelius B, Eliasson B, Rosengren A Gudbjornsdottir S. Association between socioeconomic status and mortality, cardiovascular disease, and cancer in patients with type 2 diabetes. JAMA Intern Med. 2016;176(8):1146-1154.

9. Nationella Diabetesregistret. Årsrapport. 2011 års resultat. 2012.

10. Zethelius B, Eliasson B, Eeg-Olofsson K, Svensson AM, Gudbjornsdottir $\mathrm{S}$, Cederholm J. A new model for 5 -year risk of cardiovascular disease in type 2 diabetes, from the Swedish National Diabetes Register (NDR). Diabetes Res Clin Pract. 2011;93(2):276-284.

11. NGSP. 2017; http://www.ngsp.org/index.asp. Accessed May 282017.

12. Socialstyrelsen. Nationella riktlinjer-Utvärdering 2015. Diabetesvård. Indikatorer och underlag för bedömningar. Stockholm: Socialstyrelsen; 2015.

13. Friedewald WT, Levy RI, Fredrickson DS. Estimation of the concentration of low-density lipoprotein cholesterol in plasma, without use of the preparative ultracentrifuge. Clin Chem. 1972;18(6):499-502.

14. (NOMESCO) NM-SC. NOMESCO classification of surgical procedures. Vol 87: Nordic Centre for Classifications in Health Care, WHO Collaborating Centre for the Family of International Classifications in the Nordic Countries; 2009. 
15. Bjork J, Grubb A, Sterner G, Nyman U. Revised equations for estimating glomerular filtration rate based on the Lund-Malmo study cohort. Scand J Clin Lab Invest. 2011;71(3):232-239.

16. Walker RJ, Gebregziabher M, Martin-Harris B, Egede LE. Quantifying direct effects of social determinants of health on glycemic control in adults with type 2 diabetes. Diabetes Technol Ther. 2015;17(2):80-87.

17. Sikio M, Tykkylainen M, Tirkkonen $H$, Kekalainen $P$, Dunbar J, Laatikainen T. Type 2 diabetes care in North Karelia Finland: do arealevel socio-economic factors affect processes and outcomes? Diabetes Res Clin Pract. 2014;106(3):496-503.

18. Sundquist K, Chaikiat A, Leon VR, Johansson SE, Sundquist J. Country of birth, socioeconomic factors, and risk factor control in patients with type 2 diabetes: a Swedish study from 25 primary health-care centres. Diabetes Metab Res Rev. 2011;27(3):244-254.

19. Bebb C, Kendrick D, Stewart J, et al. Inequalities in glycaemic control in patients with type 2 diabetes in primary care. Diabet Med. 2005;22(10):1364-1371.

20. Guthrie B, Emslie-Smith A, Morris AD. Which people with type 2 diabetes achieve good control of intermediate outcomes? Population database study in a UK region. Diabet Med. 2009;26(12):1269-1276.
21. Wong KW, Ho SY, Chao DV. Quality of diabetes care in public primary care clinics in Hong Kong. Fam Pract. 2012;29(2):196-202.

22. Emilsson L, Lindahl B, Koster M, Lambe M, Ludvigsson JF. Review of 103 Swedish healthcare quality registries. J Intern Med. 2015;277(1):94-136.

23. Eliasson B, Gudbjörnsdottir S. Diabetes care-improvement through measurement. Diabetes Care. 2014;106(Supplement 2):S291-S294.

\section{SUPPORTING INFORMATION}

Additional Supporting Information may be found online in the supporting information tab for this article.

How to cite this article: Julin B, Willers C, Leksell J, et al. Association between sociodemographic determinants and health outcomes in individuals with type 2 diabetes in Sweden. Diabetes Metab Res Rev. 2018;34:e2984. https://doi.org/ 10.1002/dmrr.2984 